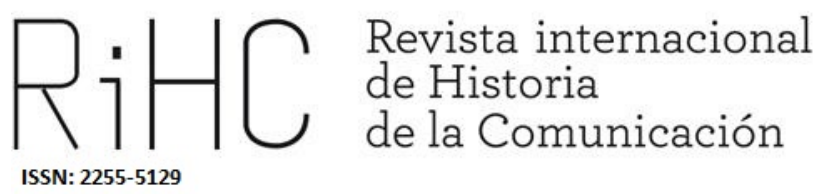

\title{
PRESENTACIÓN DOSSIER: PRENSA Y EMIGRACIÓN ESPAÑOLA EN AMÉRICA
}

DOI: http://dx.doi.org/10.12795/RiHC.2019.i12.01

Concepción Navarro Azcue

Universidad Complutense de Madrid, España

navarro.azcue@yahoo.es

ORCID (iD) 0000-0002-1080-1325 
A pesar de que la emigración a América constituye una de las variables demográficas estructurales más importantes en el devenir español, la investigación histórica no estuvo muy interesada en ella. La conexión con las nuevas repúblicas americanas permitió desarrollar unos flujos migratorios pendulares que conectaron en los siglos XIX y XX España con América, y que, en el siglo XXI, han conectado América con España, en un juego de procesos en espejo. Sin embargo, todo este entramado no despertó el interés de los académicos y tenemos que esperar a los años 70 del siglo veinte para empezar a visibilizar el fenómeno. Así es; los trabajos de Nicolás Sánchez Albornoz actuaron de pioneros en este nuevo interés, pero será la conmemoración del Quinto Centenario del Descubrimiento de América la que actuará de acicate, no solo para el mundo académico, sino, también, para las autoridades nacionales y autonómicas, en un afán por recuperar un pasado común muy rico en experiencias y en aportes de toda índole: económica, cultural, social, y política, entre otras. De este modo, el fenómeno de las migraciones, conforme iban progresando los estudios de historia demográfica, económica y social en los últimos decenios, atraía el interés creciente de la investigación histórica. Se crearon revistas especializadas, que se dedican exclusivamente al estudio de los aspectos teóricos, cuantitativos, económico-sociales, etc. de los procesos migratorios, tanto en la actualidad como en el pasado. Los académicos fueron ampliando sus intereses, desde los primigenios de la caracterización del fenómeno, hasta los que hoy protagonizan las nuevas corrientes historiográficas, como son el asociacionismo, el liderazgo étnico, la acción cultural y la prensa étnica, entre otros.

La disparidad de temáticas que enriquecen magníficamente este volumen, significan, también, un reto a la hora de abordar la presentación del mismo. Por ello, hemos considerado más interesante hacer este abordaje desde el punto de vista de nuestra especialización, es decir, la Historia, aun comprendiendo que en él se aportan trabajos desde otras disciplinas. El denominador común es el interés por utilizar la prensa como recurso heurístico y hermenéutico en este volumen, para analizar estudios de caso relacionados con la prensa y las publicaciones que desarrollaron las colectividades migrantes. Lo primero que cabría resaltar en las posibilidades que para el estudio ofrece la prensa es la capacidad que tiene de expresar, entre otros fenómenos, los eventos cotidianos. Estos son fundamentales para la comprensión del impacto que tiene un hecho relevante en lo local, e n la sociedad receptora e, incluso, en relación al país de origen, pues los vínculos con la sociedad de origen, lejos de desaparecer, se intensifican con el transcurso de los años, en la medida en que el flujo migratorio se mantenga en volúmenes importantes. Estos vínculos se manifiestan en numerosas vertientes: educación, economía, religión, comunicación, sociedad, y cultura, entre otras. Por ello, en referencia a la prensa migratoria como universo de análisis, es importante constatar el potencial hermenéutico en el que se analizan las colectividades migrantes, la sociedad receptora y las sociedades de procedencia con estudios de la 
Historia en clave multidisciplinar: económica (mercados étnicos con productos de los países de origen, empresas, anuncios de productos), social (clase obrera organizada en gremios y sindicatos, movimientos sociales y actividades en función del colectivo), política (ideología que incide en el voto por uno u otro candidato, criticar al gobierno vigente...) y cultural, a partir de obras literarias, eventos culturales, cinematografía, arte, música, danza y redes regionales, entre otras, e incluso de las mentalidades. Por todo ello el periódico se convierte a la vez en objeto y fuente.

Así mismo, en el ámbito americano, objeto de estudio de este volumen, el periodismo y los periódicos cumplieron una misión muy importante en la constitución de los nuevos Estados Nacionales y en la transformación social de los pueblos. Todos los diarios, cada uno con su idea, constituían una comunidad específica cuya labor conjunta enriquecía e instruía a toda la comunidad. Este pensamiento estuvo arraigado en las élites políticas e intelectuales. La misión que la prensa debía tomar estaba vinculada a una idea iluminista, pedagógica y civilizatoria. Desde esta mirada de época, se entendía esta misión, y a partir de ella, las lecturas, los debates y las prácticas que de allí surgían eran visualizadas como elementos pedagógicos, a través de las cuales el "pueblo", protagonista principal de la "soberanía popular", se educaba y participaba de las virtudes de la civilización y de la República. Junto a esta labor, la prensa formó parte de un proceso fundacional de la comunidad política en la que sus integrantes compartieran y practicaran, sobre nuevas bases, postulados políticos y filosóficos.

El periódico se convierte así en registro flexible de la historia y, a la vez, en un actor del proceso comunicativo. Sin embargo, su tratamiento requiere un marcado espíritu crítico y el conocimiento del contexto histórico en el que se desarrollan las publicaciones estudiadas.

A continuación, iremos desgranando cada uno de los trabajos que tenemos que presentar, para acercarnos a unas aportaciones tan sustanciosas que permiten, a través de estudios de caso, aproximarnos a la temática de la prensa étnica desde distintos ámbitos geográficos, ángulos y perspectivas.

Oscar Álvarez Gila en su investigación nos acerca al desarrollo de la prensa de la diáspora vasca desde su nacimiento, a fines de la década de 1879, hasta el periodo de la Guerra Civil. Con ello permite ver cómo la prensa tuvo un impacto considerable, a través de la redefinición del entramado periodístico por el aporte de los exiliados, afirmando que aquella tuvo un gran peso en el proceso de construcción de la identidad diaspórica vasca. Para ello ha escudriñado distintas publicaciones en cinco países: Argentina, Uruguay, Cuba, México y Chile. Este ejercicio le ha dado al autor una valoración panorámica del proceso, y la posibilidad de conocer quiénes eran los promotores de estos emprendimientos, centros o empresarios particulares, los contenidos, las líneas ideológicas de las publicaciones, entre otros aspectos 
fundamentales a la hora de valorar el peso de esta prensa en la creación y recreación de la identidad vasca.

En el artículo de Miguel Ángel Hernández el autor nos explica cómo, entre la prensa neoyorquina del siglo XIX, nacieron una serie de periódicos publicados en castellano para defender los intereses españoles en la gran ciudad. Su objetivo era hacer de balanza ante los ataques antiespañolistas de la prensa de los exiliados cubanos. El autor nos acerca a la comprensión de que la unión de distintas y variadas ideologías, con el fin de actuar al unísono ante el reto independentista, permitió llevar a buen fin el objetivo identitario español, tan necesitado de un apuntalamiento en un escenario americano, tanto del norte como del sur, tan poco proclive a todo lo que sonara a español a finales del siglo XIX.

El trabajo de Julio Yanes nos permite abordar una temática, también relacionada con Cuba, pero protagonizada por una colectividad migrante regional, la canaria. EI trabajo nos acerca al perfil de la minoría editora, la tipología y la evolución del producto informativo, la distribución y circulación de los ejemplares, los destinatarios y receptores de la información e, incluso, los cauces a través de los cuales circuló el mensaje por la colectividad canaria en Cuba, pero también en la propia sociedad canaria. Como en el anterior trabajo sobre la diáspora vasca, la construcción de una identidad nacionalista canaria se vivió con vibrante emoción desde un escenario fuera del de las islas, en contraste con un posicionamiento menos radical en el interior de las mismas. Finalmente, el autor nos permite valorar la importante aportación que hicieron los emigrantes españoles en general, y los canarios para este caso particular, en la conformación de la prensa en América, como divulgadora de opiniones y conformadora de ideologías.

La investigación de Emelina Martín Acosta nos vuelve a conectar con la colectividad canaria en Cuba y su proceso de afirmación identitaria a través de la revista EI Guanche. La colectividad se nutría de la información de sus publicaciones para estar ilustrada del devenir de los migrantes, pero, también, de los personajes que venían de la tierra de origen, así como, de lo que sucedía en la sociedad receptora. El nacionalismo lo presentaba la revista como una corriente de pensamiento y de acción política especial, que provenía de una aspiración democrática y cuya exaltación de los valores nacionales iban encaminados a la defensa de la identidad como pueblo. En este escenario la revista El Guanche fue un ejemplo de activista en la defensa de Canarias en general, y en el caso que se presenta en esta aportación, de la figura de Unamuno y la aportación que hizo éste a la propia revista a través de los artículos publicados en la misma.

La aportación de Prudencio Viveiro nos acerca a la prensa de la emigración gallega a América al presentar una panorámica de esta colectividad, sus volúmenes, características y valoración, no solo cuantitativa, sino cualitativa de la misma. La 
emigración ha supuesto para Galicia un factor estructural en todos los órdenes de su entramado como sociedad. Así mismo, la sociedad gallega en origen buscó en las colectividades migrantes un apoyo fundamental para su propio desarrollo, manteniendo una relación estrecha, que en muchos casos se va a ver potenciada con la utilización de la prensa como vehículo fundamental en esta interrelación. Este trabajo nos permite apreciar cómo la prensa gallega en el exterior cumplió una misión de intermediaria entre las sociedades gallegas de las dos orillas del Atlántico.

Alicia San Martín nos aproxima a un intelectual polifacético, brillante y controvertido dentro del panorama español de principios del siglo XX. Con la excusa del estudio Vicente Blasco Ibáñez en su periplo argentino la autora nos acerca al momento de recuperación de las relaciones entre España y sus antiguas colonias, tan deterioradas en el siglo XIX. Su viaje por América, paralelo al que haría Rafael Altamira con la misma finalidad de recuperar la presencia española en aquel continente, nos permite apreciar el esfuerzo que hizo la prensa de la migración, y en este estudio de caso, El Diario Español de Buenos Aires, para potenciar un capital simbólico que permitiera afianzar la recuperación del prestigio español en América. Así es, el diario se convirtió en uno de los "gestores" de la identidad española tan necesitada de un afianzamiento, en un contienente que había potenciado la hispanofobia desde su independencia, y, para ello, se instrumentalizó a los intelectuales que a partir de estos años fueron llegando, regularmente, a América como embajadores culturales. Con este trabajo la autora nos invita a seguir investigando en personajes que permitieron dar un vuelco al panorama de las relaciones entre dos sociedades unidas por tantos lazos comunes.

Siguiendo el mismo espacio geográfico, el Cono Sur americano objeto de estudio del anterior artículo, Alejandro Fernández nos aproxima a otra revista, Ressorgiment, en este caso vinculada a la colectividad catalana. El autor nos adentra en aquellos elementos que fueron conformando una identidad catalana en América: el asociacionismo, la acción cultural de la colectividad, y su actividad política, entre otras. Así mismo, nos presenta las características de esta colectividad, que en muchos aspectos se distinguió de otras, como la gallega o la vasca, por elementos que ya venían conformándose desde el siglo XVIII. Esta revista, que tuvo también muchas críticas por parte de la colonia catalana enfrentada con el nacionalismo, representó un ejemplo para otras de la misma identidad en espacios americanos como Montevideo, La Habana y Santiago de Chile, donde ilustró cómo avanzar en la conformación de estrategias en un reforzamiento identitario en el exterior. Sus relaciones con las colectividades de estos centros, además del propio de Argentina, sirvieron como vehículo de este interés al conformarse en portavoz del nacionalismo catalán, que igualmente se vio reforzado con la llegada de los exiliados catalanes de la Guerra Civil española. 
Frente al caso anterior de una revista catalana que utilizó su espacio para manifestar su enfrentamiento con el bando nacional de la Guerra Civil española, el trabajo de Nadia de Cristóforis nos invita a bucear en el análisis de dos publicaciones proclives a los sublevados en Buenos Aires. La colectividad gallega en Argentina presentaba volúmenes muy considerables, siendo la más importante dentro la emigración española a América en todos los espacios del continente. Este estudio de caso nos permite concluir que, en todos los países donde la emigración española se manifestaba con una presencia importante, la Guerra Civil provocó notables enfrentamientos por el enconamiento de las posturas. Así es, no quedó resquicio para el diálogo ni para el entendimiento y éstas se radicalizaron con la misma velocidad que el propio enfrentamiento militar. Las dos publicaciones, a través de un importante esfuerzo propagándístico, se posicionaron por el bando nacional e intentaron servir como elementos catalizadores dentro de la colectividad, pero, al mismo tiempo, como factores de consolidación del franquismo en la patria de origen.

La investigación de Marcelo Garabedian presenta un estudio de caso muy interesante porque nos permite acercarnos a una publicación desarrollada en un espacio, Chile, donde la emigración española no fue tan mayoritaria, como en Argentina, Brasil, Uruguay o Cuba. Además, esta colectividad se focalizó sobre todo en la capital y en Valparaíso, de ahí la relevancia de este trabajo. El autor hace un gran esfuerzo al trabajar una publicación, que representa un ejemplo de las limitaciones con las que se encontraban los españoles a la hora de asumir un emprendimiento nuevo relacionado con la prensa, por el exiguo número de potenciales usuarios. Así mismo, aunque su objetivo sea analizar La Voz de España, el autor nos adentra en el mundo de las publicaciones españolas en Chile a través de una mención pormenorizada de algunas otras. Por ello, podemos apreciar que estas publicaciones presentaron fisuras a la hora de posicionarse en relación con la política de la patria lejana, y este enunciamiento de los discursos políticos resultaba, en el análisis del autor, así mismo, chocante dentro de la sociedad chilena.

Oleguer Vall utiliza un estudio de caso para adentrarnos en la política de acción cultural para recuperar las relaciones de España con América, como ya hemos mencionadoa al presentar el trabajo de Alicia San Martín. Así es, en 1907 España había hecho una apuesta importante al fundar la Junta de Ampliación de Estudios (JAE) que tenía, entre otras misiones, recuperar las relaciones culturales con las antiguas colonias, para lo que diseñó una estrategia de concesión de becas y de institucionalización de estancias de profesores españoles en América. El autor nos menciona a la Institución Cultural Española en Montevideo, fundada en 1918 y vinculada a esta estrategia de la JAE, a través de la cual, y en consonancia con su homóloga en Buenos Aires, invitaron a dar cursos y conferencias en Montevideo a lo mas granado de la intelectualidad española del momento. En este escenario, ya tan 
positivo en relación con la hispanofobia del siglo XIX, el mensuario Vida Canaria representa un gran esfuerzo por parte de una colectividad, que en esos momentos ya no era mayoritaria, dentro de la emigración española en Montevideo, aunque, no podemos olvidar, que oriundos de las islas fueron los primeros pobladores $y$, por tanto, fundadores de Montevideo. En este mensuario se articularon escenarios ideológicos que se conformaban, tanto en la colectividad canaria en Uruguay, como en los de los propios canarios en las islas, percibiéndose dos etapas muy marcadas desde este punto de vista.

La investigación que presentan Emilio Redondo y Elda González nos permite abordar aspectos relacionados con otra de las colectividades españolas mayoritarias en América, en este caso la de Brasil. Desde mediados del siglo XIX, Brasil comenzó a recibir una gran afluencia de inmigrantes de origen español, dirigida en su mayoría al estado de São Paulo. Allí fueron empleados como mano de obra en la recolección de café, en unas condiciones de trabajo que no distaban mucho de la esclavitud, que todavía tardaría en abolirse, pues sería el último país americano en hacerlo en 1888. Ya a comienzos del siglo siguiente los periódicos locales de la colectividad española denunciaron ante la opinión pública los abusos a los que los colonos eran sometidos, por parte de los propietarios de las facendas. La prensa en España, y la de Madrid y Galicia en particular, se hizo eco de esas denuncias, causando tal alarma social, que el gobierno decidió prohibir temporalmente la emigración al Brasil. En este artículo los autores analizan el contradictorio papel que El Diario Español desempeñó en relación con este problema, porque, si por una parte sus denuncias empujaron al gobierno de la patria de origen a tomar cartas en el asunto, por otro lado, sembraron la duda al afirmar que estas denuncias pudieran no estar sustentadas en la verdad. Los autores concluyen aseverando que la prensa étnica no buscó siempre el beneficio de la colectividad en su conjunto.

El trabajo de Ángel Fernández Arriola nos acerca a otro escenario americano, en este caso México, que, como en la presentación sobre Chile, nos permite analizar colectividades poco numerosas, lo cual, para un enfoque comparativo, resulta muy clarificante. El autor hace un ejercicio de enorme reflexión al analizar una figura tan compleja y no considerada en su totalidad como es la de Emilio Rey. Así es, por una parte, no ha sido considerado hasta ahora como hombre de letras cantábricas, pero, por otra, tampoco ha sido valorado como un escritor netamente mexicano. El autor planea sobre su participación dentro de las instituciones culturales y públicas de México, pero así mismo, le situa en el escenario mexicano de la época en los ámbitos políticos, sociales y culturales. En éstos analiza sus posicionamientos, que a veces resultan chocantes y pendulartes. En este esfuerzo por analizar una figura un tanto compleja el autor se acerca a su faceta de periodista, literato, poeta y novelista, a pesar de que sus trabajos en esta línea no tuvieron la suficiente trascendencia en el mundo literario mexicano, por el medio de comunicación en el 
que publicó sus obras. En definitiva, este trabajo nos permite comprender la complejidad de la vida de muchos de los intelectuales que se trasladaron a América, que nunca fueron considerados, ni como españoles, ni como pertenecientes a la nueva patria de destino.

El artículo de Lilia Vieyra aborda, nuevamente, un estudio de caso centrado en el análisis de un personaje, en esta ocasión el asturiano Juan de la Fuente Parres, en su faceta de editor del periódico La Prensa. Sin embargo, al revés que en el caso de Emilio Rey, éste si fue reconocido por la intelectualidad mexicana. La autora nos permite navegar por la significación de esta figura al presentarnos sus distintos emprendimientos empresariales vinculados al rubro de las editoriales, y la labor cultural en la patria de destino. A través de la prensa la autora ha podido reconstruir la biografía de este personaje desde su tierra natal, su llegada y desarrollo vital en México, donde se detiene en enfatizar la importancia de la labor periodística que De la Fuente realizó en La Prensa entre 1883 a 1884, año de transición entre el gobierno de Manuel González y Porfirio Díaz. Esa etapa será trascendental para De la Fuente porque se presentará en el ambiente cultural y político mexicano y trabajará con escritores liberales. Pero en México no solo se embarcaría en actividades editoriales, sino, además, en otras vinculadas al mas puro capitalismo en su faceta de rico hacendado, lo cual representa una puerta abierta al estudio de otros migrantes asturianos en América, cuyo perfil acusa una balanza, netamente, exitosa.

María del Mar Gutierrez nos presenta una investigación, de mas amplio espectro, pero también vinculada al periodismo étnico español en México en los finales del siglo XIX. En ella igualmente se aprecia la relación que estos profesionales de la prensa establecieron con la sociedad y el ámbito cultural mexicano. Esta relación no fue en todos los casos de parecido resultado, y más cuando los estudiados por Gutiérrez son exiliados del republicanismo federal español de los años 80 coincidente con el Porfiriato mexicano, no precisamente un dechado de virtudes democráticas. A pesar de este escenario la autora nos deja claro que estos intelectuales fueron "comprensivos", aunque con distintos compromisos, con el Porfiriato. Así mismo, nos permite ver los entresijos que sus publicaciones reflejaban respecto a la configuración interna de la colonia, y los propios cambios políticos que se producían en la patria de origen. También, nos acerca a los enfrentamientos de los exiliados pues, aunque todos eran federalalistas, sus planteamientos, respecto a la cuestión social, diferían mucho de un diálogo desapasionado. Además, es importante resaltar el aire nuevo que estos exiliados trajeron en relación al conservadurismo que presentaba la colectividad española en México y los desencuentros de áquellos con ésta, y cómo este mismo escenario se volvería a producir, en el siglo siguiente, con el exilio intelectual de la Guerra Civil. 
Por último, el trabajo de Lydia Elizalde nos vuelve a enfrentar con un estudio de caso, El Correo Español de México en los finales el siglo XIX. En este período la prensa comenzó a convertirse en conformadora de opiniones, pero también, en divulgadora cultural. El emprendimiento comenzó en Europa, pero América, en algunos espacios, le siguió al servir como espejo de corrientes positivistas. La autora nos presenta una serie de trabajos publicados en este diario, pero que no son un caso aislado, porque estas publicaciones constituyeron el medio de dar a conocer a la sociedad la obra de poetas, novelistas y narradores, en general. Las colaboraciones literarias en este diario no solo se hicieron desde las filas de intelectuales españoles, sino, y en una importante cantidad, desde las filas de creadores mexicanos que no siempre pertenecían a la intelectualidad, pues entre ellos hay notarios, empresarios, funcionarios públicos, etc. Finalmente, nos parece importante resaltar que la autora pone en valor la prensa como fuente, a veces única, para el conocimiento de esta acción cultural y, que no ha sido, prácticamente, estudiada, aspecto que todos los que nos dedicamos a esta línea historiográfica querríamos resaltar.

No queremos finalizar nuestra presentación sin poner de manifiesto la positiva valoración que hacemos de estas investigaciones, pues representan magníficos aportes en una línea historiográfica tan novedosa, como es la utilización de la prensa como recurso heurístico y hemenéutico, para el estudio de los flujos migratorios. Esta línea que está siendo utilizada de una manera transversal por distintos investigadores del campo de la Comunicación, del Derecho, la Economía, la Historia, la Sociologia, la Antropología, entre otros, permite esperar que en los próximos años la colaboración de todas estas disciplinas ofrezca excelentes frutos. 